\title{
Atrioventricular conduction in patients with clinical indications for transvenous cardiac pacing ${ }^{1}$
}

\author{
Stafford I. Cohen, L. Kent Smith, Julian M. Aoresty, Panagiotis Voukydis, and Eugene Morkin \\ From the Cardiac Unit, Department of Medicine, Beth Israel Hospital and Harvard Medical School, Boston, \\ Massachusetts, U.S.A.
}

\begin{abstract}
Eighty patients with clinical indications for cardiac pacing had atrioventricular conduction analysed by His bundle study. The indications for cardiac pacing included high grade atrioventricular block, sick sinus node syndrome without tachycardia, bradycardia-tachycardia syndrome, unstable bilateral bundle-branch block, and uncontrolled ventricular irritability.

Complete heart block, Wenckebach block (Mobitz I), and 2:I block were noted proximal and distal to the His bundle. Mobitz II block only occurred distal to the His bundle. Of special interest were the high incidence of distal conduction abnormalities by His bundle analysis (40/80, 50\%), the re-establishment of normal atrioventricular conduction in acutely ill patients with recent evidence of heart block, and the high incidence of intraventricular conduction disturbances on standard electrocardiogram $(48 / 80,60 \%)$.
\end{abstract}

Intensive study of atrioventricular conduction by His bundle analysis has been performed in a variety of patient populations. In many instances studies were electively undertaken in patients who had never been threatened by a compromising cardiac arrhythmia. In addition, abnormalities of atrioventricular conduction were frequently achieved by pacemaker-induced acceleration of the atrial rate. The purpose of this study was to characterize atrioventricular conduction in a group of patients who had clinical indications for a cardiac pacemaker. Atrioventricular conduction was analysed by His bundle electrogram in 80 patients who were referred for transvenous cardiac pacing. The clinical indications for cardiac pacing included third degree block, second degree block, sick sinus node syndrome without tachycardia, bradycardia-tachycardia syndrome, unstable bilateral bundle-branch block, and uncontrolled ventricular irritability. Data pertaining to atrioventricular conduction were obtained during the course of transfemoral venous pacemaker insertion. The characteristics of atrioventricular conduction were noted as well as standard electrocardiographic evidence of remote or current intraventricular conduction disturbances.

The presentation of the analysis of the naturally

Received 28 October 1974.

${ }^{1}$ Supported in part by a training grant from the National Heart and Lung Institute. occurring electrophysiological data in this large group of patients in clinical need of pacemakers constitutes the substance of this report. The data should be representative of the cardiac conduction abnormalities which present in a general hospital.

\section{Subjects and methods}

Atrioventricular conduction was studied in 80 patients referred for temporary or permanent cardiac pacing. Temporary transvenous pacing was performed via the transfemoral route with a No. 5 bipolar catheter. The ring electrodes were $2 \mathrm{~mm}$ in width and spaced $\mathrm{I} \mathrm{cm}$ apart. His bundle electrograms were obtained by standard methods and were recorded on an 8-channel Electronics for Medicine oscilloscope recorder. Acutely ill patients had temporary pacemakers inserted and electrophysiological study conducted in the cardiac catheterization laboratory or the intensive care unit. Study in the latter area was facilitated by the use of a fluoroscopic bed and image intensifier. All permanent pacemakers were implanted in the cardiac catheterization laboratory. Patients who required permanent pacemaker revision or replacement had a No. 5 bipolar temporary transfemoral catheter positioned for electrical control during the procedure.

Bipolar electrograms were obtained by standard methods which defined atrial excitation (A), His bundle excitation (H), and ventricular excitation (V) (Scherlag et al., 1969, 1970; Damato et al., 1969; Damato and Lau, 1970; Scherlag, Samet, and Helfant, 1972). His bundle electrograms were validated either by an increase in the AH interval during spontaneous or induced atrial 
TABLE I

\begin{tabular}{llll}
\hline Case Sex & Age & $\begin{array}{l}\text { His bundle electrogram } \\
\text { AH(ms) }\end{array}$ \\
No. & & HV (ms) \\
\hline
\end{tabular}

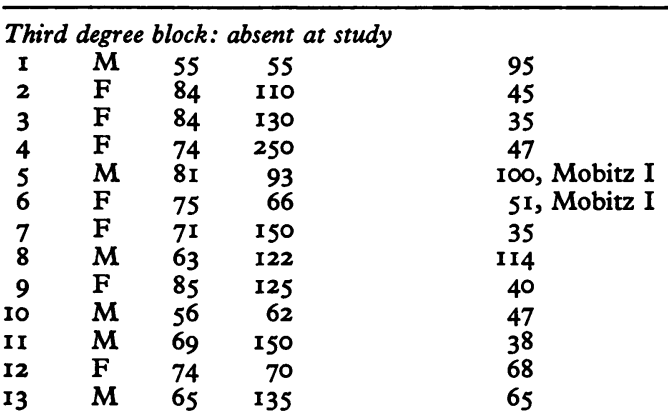

Third degree block: present at study

\begin{tabular}{|c|c|c|c|c|}
\hline & & & & \\
\hline 14 & $\mathbf{F}$ & 81 & 95 & - \\
\hline I5 & $\mathbf{F}$ & 84 & 100 & - \\
\hline I6 & M & 81 & 200 & - \\
\hline 17 & $\mathbf{M}$ & 83 & - & - \\
\hline 18 & $M$ & 74 & 87 & - \\
\hline 19 & $\mathbf{F}$ & 75 & 66 & - \\
\hline 20 & $M$ & 77 & - & - \\
\hline $2 I$ & $M$ & 80 & 130 & 一 \\
\hline 22 & $M$ & 76 & 127 & 二 \\
\hline $\begin{array}{l}23 \\
24\end{array}$ & $\begin{array}{l}\mathbf{M} \\
\mathbf{M}\end{array}$ & $\begin{array}{l}73 \\
76\end{array}$ & $\begin{array}{r}115 \\
88\end{array}$ & - \\
\hline $\begin{array}{l}24 \\
25\end{array}$ & $\mathbf{F}$ & 77 & 130 & - \\
\hline 26 & $\mathbf{M}$ & 70 & - & - \\
\hline 27 & $\mathbf{F}$ & 75 & - & - \\
\hline 28 & $\mathbf{F}$ & 74 & - & - \\
\hline 29 & $\mathbf{M}$ & 68 & 92 & - \\
\hline 30 & $\mathbf{M}$ & 86 & 一 & - \\
\hline 3I & $\mathbf{M}$ & 6I & 145 & - \\
\hline \multicolumn{5}{|c|}{ Second degree block: absent at study } \\
\hline 32 & $\mathbf{M}$ & 60 & 125 & 70 \\
\hline 33 & $\mathbf{F}$ & 86 & 105 & 140 \\
\hline 34 & $\mathbf{F}$ & 79 & 120 & 40 \\
\hline 35 & $\mathbf{F}$ & 84 & 125 & 100 \\
\hline \multicolumn{5}{|c|}{ Second degree block: present at study } \\
\hline 36 & $\mathbf{M}$ & 68 & IOI & $67,2: 1$ \\
\hline 37 & $\mathbf{M}$ & 86 & 253, Mobitz I & 49 \\
\hline 38 & $\mathbf{F}$ & 80 & 232, Mobitz I & 45 \\
\hline 39 & $\mathbf{F}$ & 83 & $145,2: 1$ & $4 \mathrm{I}$ \\
\hline 40 & $M$ & 77 & 102 & $75,2: 1$ \\
\hline 4I & $\mathbf{F}$ & 80 & 87 & $87,2: I$ \\
\hline 42 & $\mathbf{F}$ & 80 & 148 & $53,2: 1$ \\
\hline 43 & $\mathbf{F}$ & 79 & $120,2: I$ & 53 \\
\hline 44 & $M$ & $7 I$ & 62 & 57, Mobitz II \\
\hline 45 & $M$ & 6I & 66 & 77, Mobitz I \\
\hline 46 & $\mathbf{F}$ & 84 & 88 & 75, Mobitz I \\
\hline 47 & $\mathbf{F}$ & 84 & 99 & 80, Mobitz I \\
\hline 48 & $\mathbf{F}$ & 65 & IOI & I ro, Mobitz I \\
\hline 49 & $\mathbf{M}$ & 43 & I20, Mobitz I & 58 \\
\hline 50 & $\mathbf{M}$ & 66 & 375, Mobitz I & 47 \\
\hline \multicolumn{5}{|c|}{ Sick sinus syndrome: without tachycardia } \\
\hline $5 \mathbf{I}$ & $\mathbf{M}$ & 64 & 87 & 34 \\
\hline 52 & $\mathbf{M}$ & 72 & 150 & 40 \\
\hline 53 & $\mathbf{F}$ & 73 & 74 & 35 \\
\hline 54 & $\mathbf{F}$ & 69 & 123 & 38 \\
\hline
\end{tabular}

TABLE I (Cont'd)

\begin{tabular}{|c|c|c|c|c|}
\hline $\begin{array}{l}\text { Case } \\
\text { No. }\end{array}$ & Sex & Age & $\begin{array}{l}\text { His bundl } \\
\text { AH (ms) }\end{array}$ & $\stackrel{m}{H V(m s)}$ \\
\hline \multicolumn{5}{|c|}{ Sick sinus syndrome: without tachycardia-cont'd } \\
\hline 55 & $\mathbf{F}$ & 79 & 112 & 56 \\
\hline 56 & $\mathbf{M}$ & 83 & 150 & 55 \\
\hline 57 & $\mathbf{F}$ & 78 & 170 & 46 \\
\hline 58 & $\mathbf{M}$ & 76 & 185 & 47 \\
\hline 59 & $\mathbf{M}$ & 80 & 115 & 40 \\
\hline 60 & $\mathbf{M}$ & 86 & 126 & 43 \\
\hline 6I & $\mathbf{F}$ & 73 & 160 & 58 \\
\hline 62 & $\mathbf{F}$ & 81 & 173 & 62 \\
\hline 63 & $\mathbf{M}$ & 70 & 88 & 45 \\
\hline \multicolumn{5}{|c|}{ Bradycardia-tachycardia syndrome } \\
\hline 64 & $\mathbf{F}$ & 70 & 82 & 34 \\
\hline 65 & $\mathbf{F}$ & 72 & 120 & 57 \\
\hline 66 & $\mathbf{F}$ & 72 & 160 & 38 \\
\hline 67 & $\mathbf{M}$ & 81 & 80 & 35 \\
\hline 68 & $\mathbf{F}$ & 73 & 134 & 66 \\
\hline \multicolumn{5}{|c|}{ Bilateral bundle-branch block } \\
\hline 69 & $\mathbf{M}$ & 86 & 258 & 66 \\
\hline 70 & $\mathbf{M}$ & 78 & 140 & 80 \\
\hline 71 & $\mathbf{M}$ & 75 & 197 & 54 \\
\hline 72 & $\mathbf{M}$ & 83 & 105 & 42 \\
\hline 73 & $\mathbf{M}$ & 85 & 100 & 46 \\
\hline 74 & $\mathrm{~F}$ & 63 & 94 & 35 \\
\hline 75 & $\mathbf{M}$ & 72 & 98 & 49 \\
\hline 76 & M & 61 & 106 & 40 \\
\hline 77 & $\mathbf{M}$ & $6 I$ & 95 & 54 \\
\hline \multicolumn{5}{|c|}{ Control of ventricular ectopia } \\
\hline 78 & $\mathrm{~F}$ & 78 & 108 & 58 \\
\hline 79 & $\mathbf{M}$ & 76 & 160 & 35 \\
\hline 80 & $\mathbf{M}$ & 78 & 105 & 40 \\
\hline
\end{tabular}

premature beats (Scherlag et al., 1969) or by His bundle pacing (Scherlag et al., 1972; Narula, Scherlag, and Samet, 1970b). The AH interval generally delineated atrioventricular node conduction time, the normal range of which is 50 to $120 \mathrm{~ms}$. Measurements were made from the onset of the $A$ wave to the first clear deflection of the $\mathrm{H}$ wave. Prolongation of atrioventricular node conduction time was defined as first degree block of the atrioventricular node.

The HV interval delineated His-Purkinje conduction time, the normal range of which was taken as 35 to $54 \mathrm{~ms}$ (Kuppersmith, Krongrad, and Waldo, I973). Measurements were made from the first clear deflection of the $\mathrm{H}$ wave to the earliest onset of ventricular excitation presenting in one of several sampled standard electrocardiographic leads or the bipolar electrograms (V wave). The HV interval is one measurement of conduction through the distal specialized conduction system. Prolongation of the HV interval was defined as first degree block of the intraventricular conduction system.

All available electrocardiograms were reviewed for evidence of intraventricular conduction abnormality in the bundle-branch system. Abnormal conduction in the right bundle-branch, left bundle-branch, anterior division of the left bundle-branch, and posterior division of 
TABLE 2

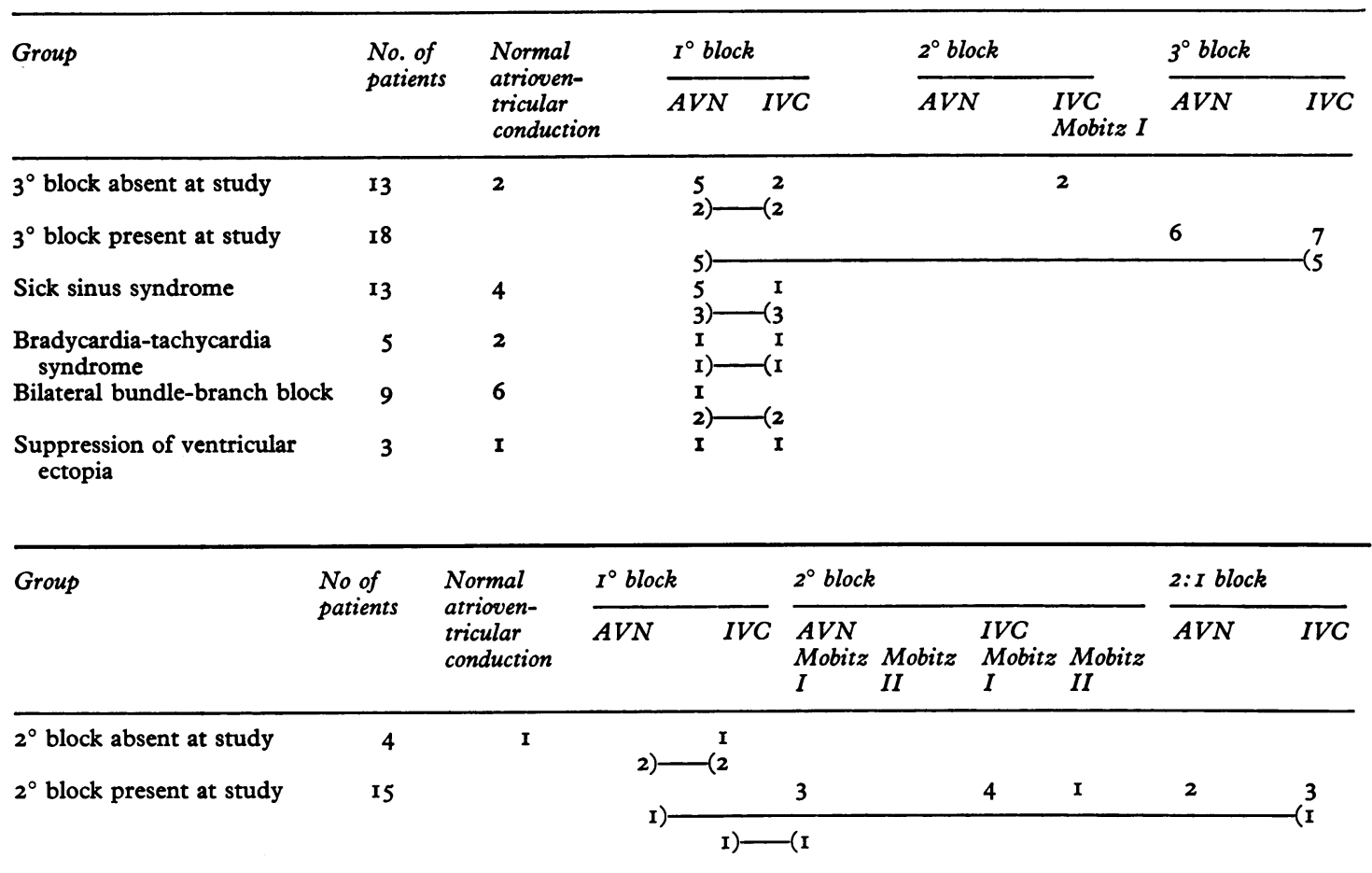

) ( This symbol indicates more than one abnormality. The number of patients with the combined abnormality are noted by the number on the open ends of the symbol.

AVN = Atrioventricular node, IVC = Intraventricular conduction.

the left bundle-branch, respectively, result in right bundle-branch block, left bundle-branch block, left axis deviation, and right axis deviation (Rosenbaum, Elizari, and Lazzari, 1970; Cohen et al., 1968). Combined disturbances in more than one conducting pathway can be recognized by combinations of these features.

The 80 patients had an average age of 75 years, with the 44 men averaging 72 years and the 36 women averaging 77 years. The patients were grouped as follows: transient third degree block absent at study (13), third degree block during study (I8), second degree block absent at study (4), second degree block during study (15), unstable bilateral bundle-branch block (9), ventricular irritability (3), sick sinus syndrome (without tachycardia) (13), and bradycardia-tachycardia syndrome (5).

\section{Results}

\section{Atrioventricular conduction}

The results of atrioventricular conduction studies are detailed in Table $I$ and summarized in Table 2. Of 13 patients with transient third degree block before study, only 2 had normal conduction at the time of study (Fig. I and 2). First degree block of the atrioventricular node was present in 5 patients. First degree block in the distal conduction system was present in 2 patients. Combined first degree block in the atrioventricular node as well as in the distal specialized conduction system was present in 2 patients. Wenckebach phenomenon (Mobitz I block) was present in the distal conducting system in 2 patients.

Fixed third degree block during study was present in 18 patients, of whom 6 had block at the atrioventricular node (failure to demonstrate a His deflection) and 12 had block in the distal specialized conducting system. Among the 12 patients who had distal block, 5 had associated first degree block in the atrioventricular node.

Transient second degree block was present before study in 4 patients. One patient had normal conduction at the time of study, I patient had first degree block in the distal conducting system, and 2 patients had first degree block of both the atrioventricular node and distal conducting system.

Second degree block was present during study in 


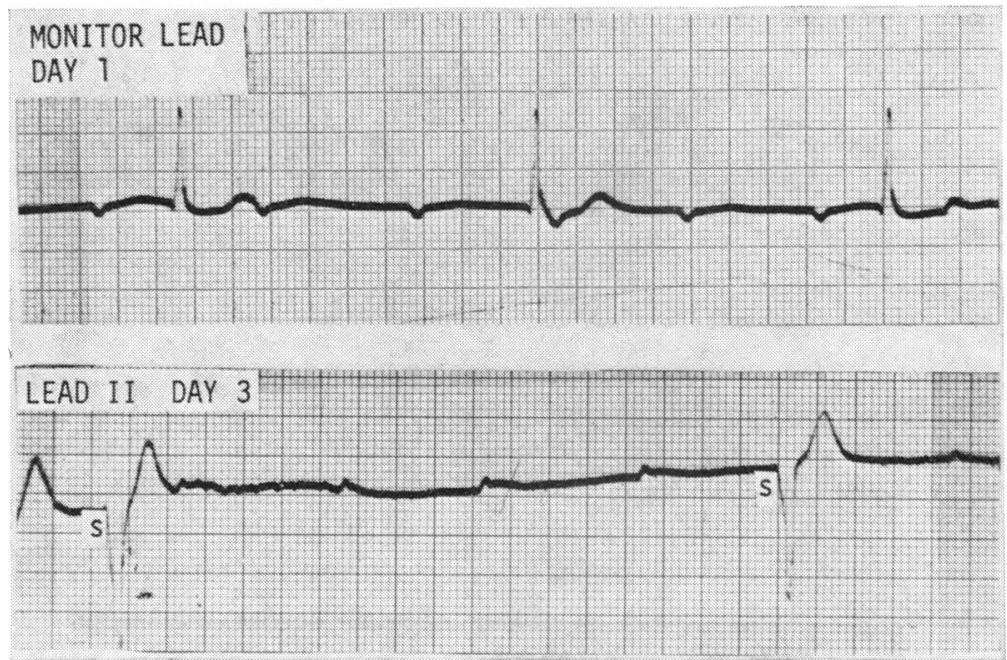

FIG. I Third degree heart block with acute myocardial infarction. Top panel: this patient entered hospital with complete heart block. Though a temporary pacemaker was promptly inserted, atrioventricular conduction had returned to normal at the time of study (Fig. 2). Bottom panel: third degree block intermittently recurred during the stay in hospital. $S=$ pacemaker stimulus induced ventricular excitation.

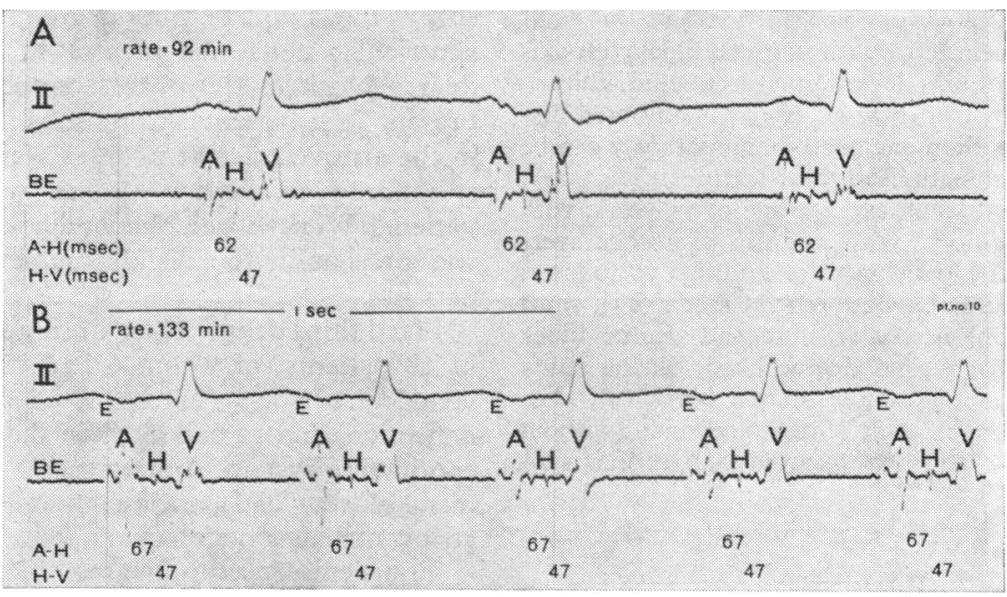

FIG. 2 Normal atrioventricular conduction shortly after third degree heart block (Fig. I). Top panel: normal atrioventricular conduction at a rate of $90 /$ minute. Bottom panel: atrioventricular conduction remains normal with acceleration of rate to 133/min by atrial pacing. Abbreviations in this and other figures: $A=$ atrial excitation. $H=H i s$ bundle excitation, $V=v e n t r i c u l a r$ excitation, $B E=$ bipolar electrogram, $E=$ atrial pacing stimulus. 
I5 patients. Wenckebach block (Mobitz I) occurred at the atrioventricular node in 4 patients (Fig. 3) and also was noted in the distal conducting system in 4 other patients (Fig. 4). One patient had Mobitz II - block in the distal conducting system (Fig. 5). Three patients had 2:I block which occurred in the distal conduction system (Fig. 6). Two patients had 2: I block of the atrioventricular node (Fig. 7). An additional patient had 2: $\mathrm{I}$ block in the distal conducting system and first degree block at the atrioventricular node.

Sick sinus node syndrome without tachycardia occurred in 13 patients. The ventricular response was correspondingly too slow to sustain a haemodynamic compensation. Four patients had normal atrioventricular conduction, 5 had first degree block of the atrioventricular node, 3 had combined first degree block of the atrioventricular node and distal conducting system (Fig. 8), and I had first degree block of the distal conducting system.

Bradycardia-tachycardia syndrome was present in 5 patients. This syndrome is characterized by sinus bradycardia which is interrupted by a variety of rapid supraventricular arrhythmias. The patients may be symptomatic during the bradycardia or during the tachycardia. Two patients had normal atrioventricular conduction, and there was one instance each of first degree block of the atrioventricular node and of the distal conduction system. The remaining patient had first degree block of both the atrioventricular node and of the distal conduction system.

Nine patients had unstable bilateral bundlebranch block. Six of this group had normal atrioventricular conduction, I had first degree block of the atrioventricular node, and 2 had combined first degree block of the atrioventricular node and distal conducting system.

Implantation of a permanent pacemaker for control of ventricular irritability was performed in three patients. One patient had prolonged HisPurkinje conduction time. Another had prolonged atrioventricular node conduction. The remaining patient had normal atrioventricular conduction.

\section{Intraventricular conduction on standard electrocardiogram}

Review of standard electrocardiograms before the development of heart block during hospitalization

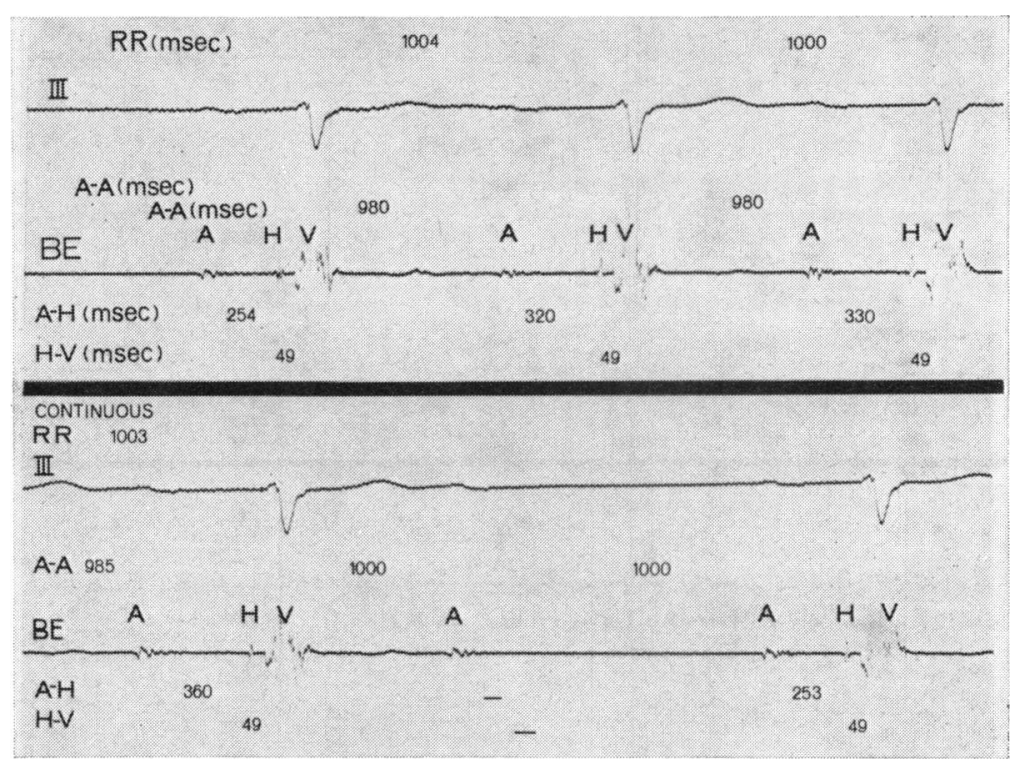

FIG. 3 Mobitz I block of the atrioventricular node. There is a progressive delay of atrioventricular node conduction. AH interval increases from $254 \mathrm{~ms}$ to $360 \mathrm{~ms}$ during four cardiac cycles until failure of transmission through the atrioventricular node. The first and last beats on the continuous recording have the shortest, though considerably prolonged, atrioventricular nodal conduction times of 254 and $253 \mathrm{~ms}$. 


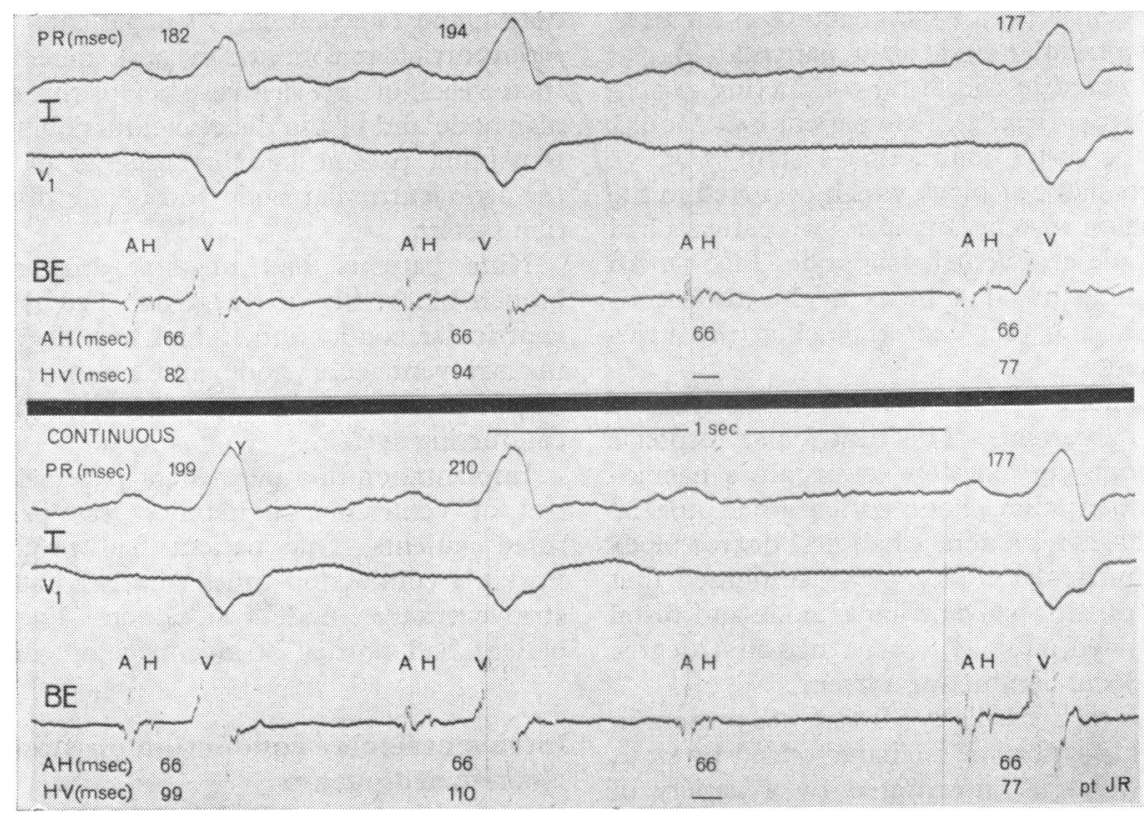

FIG. 4 Mobitz I block of the distal conduction system. There is a progressive delay of intraventricular conduction ( $H V$ interval) from $82 \mathrm{~ms}$ to $94 \mathrm{~ms}$ and from $77 \mathrm{~ms}$ to $110 \mathrm{~ms}$ during two-beat and three-beat sequences respectively, until transmission through the distal system fails. The abnormally delayed distal conduction in the first beat of each new cycle indicated first degree block of the right bundle-branch in the setting of this patient's left bundle-branch block.

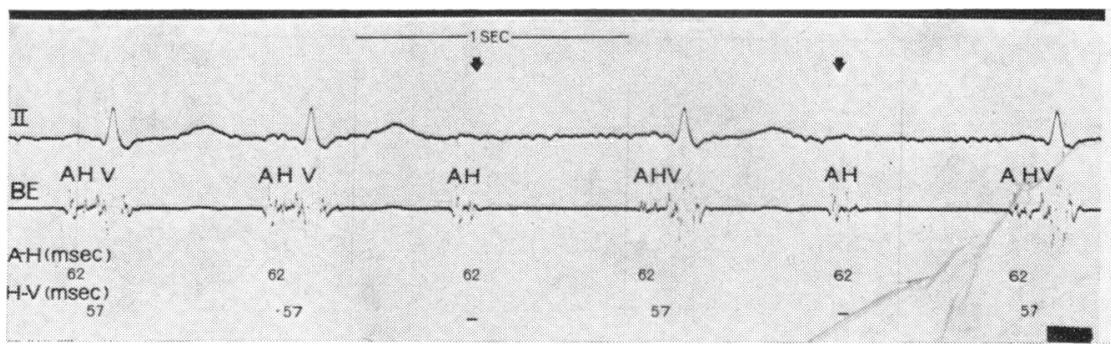

FIG. 5 Mobitz II block of distal system. There is first degree block of the distal system. The first two beats are conducted normally. Without warning, the third and fifth atrial excitations (arrows) are not conducted to the ventricles. Atrioventricular node conduction is unchanged for all beats. 


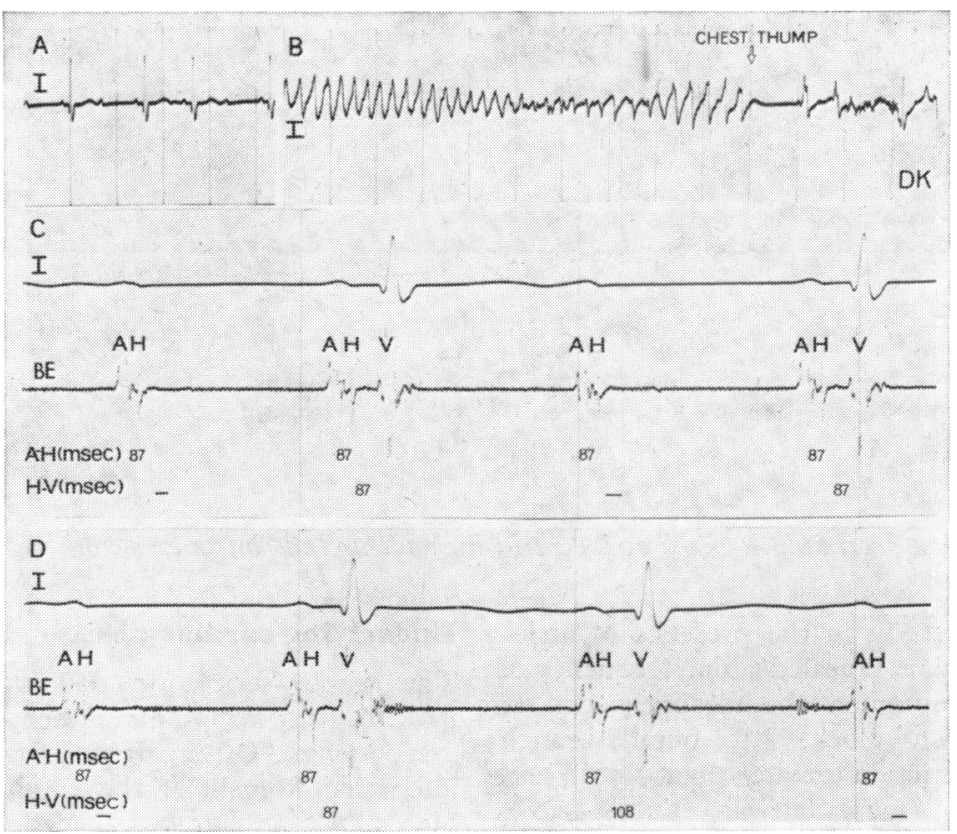

FIG. 62 2:I block and Mobitz I block in the His-Purkinje system. This patient presented with a basic 2: I block, rare episodes of Mobitz I block $(A)$, and ventricular flutter $(B)$. Intracavitary electrograms demonstrated the 2:I block and the Mobitz I block to be localized distal to the His bundle $(C, D)$. In addition, there is first degree block of the intraventricular conduction system.

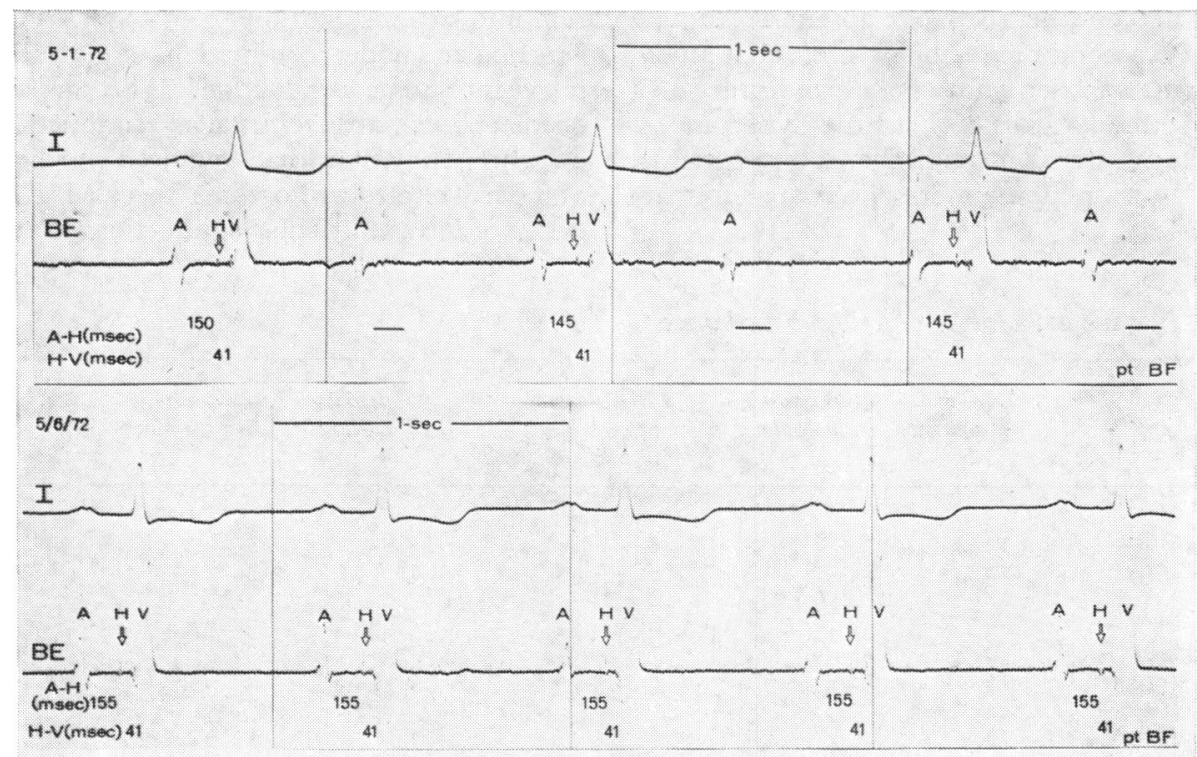

FIG. $72: 1$ block at the atrioventricular node in acute inferior myocardial infarction. Top panel demonstrates 2:I block of the atrioventricular node on the first day of acute inferior myocardial infarction. On the sixth day the atrioventricular node has recovered enough to permit $1: I$ conduction. Note a persistent first degree block at the atrioventricular node. 


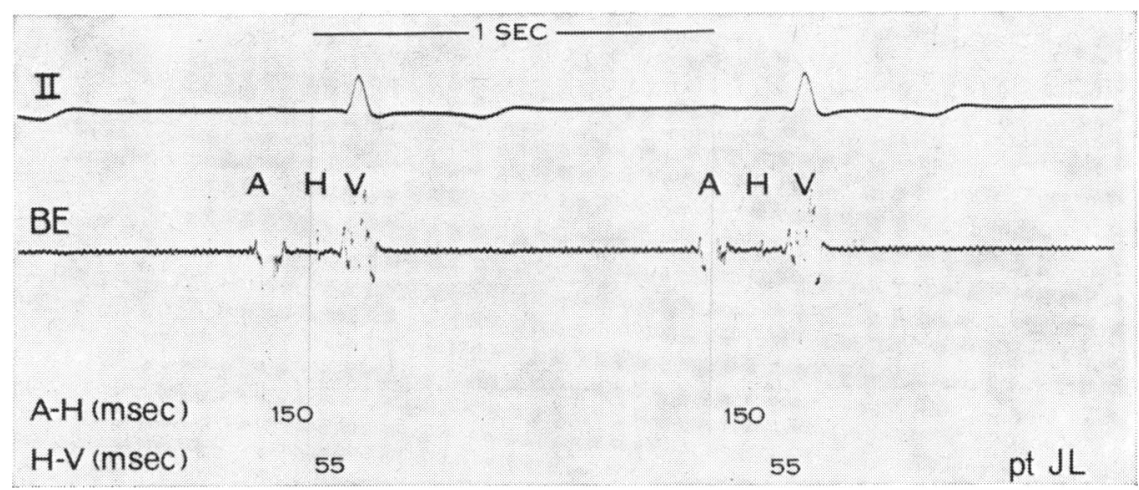

FIG. 8 First degree block of the atrioventricular node and the intraventricular system.

or at the time of study in the presence of atrioventricular conduction, revealed a high frequency of intraventricular conduction abnormalities such as right bundle-branch block, left bundle-branch block, right axis deviation (greater than $+90^{\circ}$ ), and left axis deviation (more leftward than $-30^{\circ}$ ). Right bundle-branch block with right or left axis deviation was considered a manifestation of bilateral bundle-branch block. The frequency of intraventricular conduction abnormalities in each group was as follows: third degree block absent at study, 6 of 13 patients; third degree block present at study, II of I8 patients; second degree block absent at study, 2 of 4 patients; second degree block present at study, I2 of 15 patients; sick sinus node syndrome, 4 of I3 patients; bradycardia-tachycardia syndrome, 2 of 5 patients; ventricular irritability 2 of 3 patients. The specific conduction abnormalities are summarized in Table 3.

\section{Underlying cardiac disease}

The whole series included a predominance of patients with symptoms of ischaemic heart disease (72 patients). Other diagnoses included presumed idiopathic fibrosis of the conduction system (5), high blood pressure with aortic valve disease (2), and cardiomyopathy (I).

\section{Discussion}

His bundle study separates atrioventricular conduction into two major components consisting of atrioventricular node conduction and His-Purkinje intraventricular conduction. The present study characterized atrioventricular conduction in an elderly population that required cardiac pacing. Standard electrocardiograms revealed a high incidence of intraventricular conduction delay. Isolated

TABLE 3 Intraventricular conduction disturbances

\begin{tabular}{|c|c|c|c|c|c|c|}
\hline Group & $\begin{array}{l}\text { No. of } \\
\text { patients }\end{array}$ & $\begin{array}{l}\text { Right bundle- } \\
\text { branch block }\end{array}$ & $\begin{array}{l}\text { Right bundle- } \\
\text { branch block }+ \\
\text { left axis deviation }\end{array}$ & $\begin{array}{l}\text { Left axis } \\
\text { deviation }\end{array}$ & $\begin{array}{l}\text { Left bundle- } \\
\text { branch block }\end{array}$ & $\begin{array}{l}\text { All intraven- } \\
\text { tricular conduc- } \\
\text { tion defects }(\%)\end{array}$ \\
\hline $\begin{array}{l}3^{\circ} \text { block } \\
\text { Absent at study } \\
\text { Present at study }\end{array}$ & $\begin{array}{l}\text { I3 } \\
\text { I8 }\end{array}$ & $\begin{array}{l}\mathbf{I} \\
\mathbf{2}\end{array}$ & $\begin{array}{l}2 \\
5\end{array}$ & I & $\begin{array}{l}3 \\
3\end{array}$ & $\begin{array}{l}46 \% \\
61 \%\end{array}$ \\
\hline $\begin{array}{l}2^{\circ} \text { block } \\
\text { Absent at study } \\
\text { Present at study }\end{array}$ & $\begin{array}{r}4 \\
15\end{array}$ & $\begin{array}{l}\mathbf{I} \\
\mathbf{I}\end{array}$ & $\begin{array}{l}1 \\
6\end{array}$ & 2 & 3 & $\begin{array}{l}50 \% \\
80 \%\end{array}$ \\
\hline $\begin{array}{l}\text { Sick sinus syndrome } \\
\text { Brady-tachy syndrome } \\
\text { Bilateral bundle-branch block } \\
\text { Ventricular irritability }\end{array}$ & $\begin{array}{r}13 \\
5 \\
9 \\
3\end{array}$ & & $\begin{array}{l}2 \\
\mathbf{I} \\
9 \\
\mathbf{I}\end{array}$ & $\begin{array}{l}\mathbf{I} \\
\mathbf{I}\end{array}$ & $\mathbf{I}$ & $\begin{array}{r}31 \% \\
40 \% \\
100 \% \\
37 \%\end{array}$ \\
\hline Totals & 80 & 5 & 27 & 5 & II & $60 \%$ \\
\hline
\end{tabular}


and combined atrioventricular conduction abnormalities were frequently noted during His bundle study. The two most common diffuse underlying pathological processes causing high degree heart block are fibrosis of the conduction system (Lenègre's disease) and ischaemic heart disease (Lenègre, 1962, 1964; Davies, 1971). Our population had an average age of 75 years; 90 per cent of the patients suffered symptoms of cardiac ischaemia and 60 per cent had standard electrocardiographic evidence of abnormal conduction in at least one of the major intraventricular conducting pathways.

In most patients it is likely that an ageing process of the conducting system becomes generalized before the occurrence of a clinical problem which requires pacemaker therapy (James, 1972); in spite of anatomical observations that pathological ageing processes distinguish between the atrioventricular node and remainder of the conducting system (Davies and Harris, 1969), isolated abnormalities of distal conduction as defined by HV time and isolated abnormalities of atrioventricular node conduction were found with almost equal frequency. There were 23 instances of the former and 24 instances of the latter. Fifty per cent of all patients $(40 / 80)$ had an infra-His conduction abnormality confined to the distal system or combined with a conduction abnormality of the atrioventricular node. Examples of the high frequency of distal block were as follows: second degree block of the Mobitz I variety occurred six times in the distal system (Fig. 4) and four times in the atrioventricular node (Fig. 3). 2: I block occurred four times in the distal system (Fig. 6) and twice in the AV node (Fig. 7). Mobitz II block occurred once and was in the distal system (Fig. 5). Our finding of a high incidence of distal conduction abnormality supports the findings of others in chronic third degree heart block (James, 1972; Narula et al., 1970a; Steiner et al., 1971), Mobitz II block (Narula and Samet, 1970; Narula et al., I97I ; Samet and Narula, 1970; Gupta, Lichstein, and Chadda, 1973), and sick sinus node syndrome (Samet and Narula, 1970).

Combined physiological abnormalities of the atrioventricular node and distal conduction system occurred in 17 of our patients ( $21 \%$ ), which corresponds with anatomical observations, such as Lenègre's (I964) that combined atrioventricular node and distal pathology was present in I6 per cent of 62 cases of complete heart block. Combined first degree block was documented in ro patients (Fig. 8). First degree block of the atrioventricular node occurred in combination with second degree block of the distal system in I patient and in combination with third degree block of the distal system in 5 patients. On the basis of repeated His bundle study, reference has been made to a pathological process which extended from the distal conduction system to the atrioventricular node (Narula et al., 197I; Rosen et al., 197I). The presumption of a process, such as a diffuse coronary disease, or more than one ageing process, might explain the combined conduction abnormalities of this study and in other studies (Rosen et al., 1971). James (1972) has noted that coronary disease may directly produce abnormalities of the entire conduction system and may be associated with degenerative disease of the conduction system.

\section{Normal atrioventricular conduction shortly} after atrioventricular block

Two patients with combined acute anterior and inferior infarctions, had intermittent third degree block. Though chronotropic drugs were administered, intermittent third degree block occurred before and after catheter insertion (Fig. 2) and both patients died from pump failure.

Transient second degree block occurred in another patient with an acute anterior infarction. Atrioventricular conduction was normal at the time of study. Normal atrioventricular conduction precluded localization of the site of block. However, it is likely that the rapid change from normal to abnormal atrioventricular conduction resulted from ischaemia to the conduction pathway(s) (Whiting et al., 1970; Nevins, 1972). Other parameters such as heart rate and blood pressure have been implicated in the development of ischaemic atrioventricular block (Gershengorn and Haft, 1972).

\section{Intraventricular conduction disturbances on standard electrocardiogram}

Abnormality of intraventricular conduction of the electrocardiogram varied from 31 per cent $(4 / 13)$ in the sick sinus syndrome to roo per cent $(9 / 9)$, by definition, in unstable bilateral bundle-branch block (Table 3). We have previously mentioned the high incidence of distal conduction abnormality as defined by $\mathrm{HV}$ time in third degree block (James, 1972; Narula et al., 1970a; Steiner et al., I97I) and sick sinus node syndrome (Samet and Narula, 1970). It is not surprising, therefore, to find a respective 6I per cent and 3I per cent abnormality of intraventricular conduction in standard electrocardiograms of patients in these categories. Patients in other categories uniformly had a high incidence of electrocardiographic intraventricular conduction abnormality. Bilateral bundle-branch block in association with third degree block has been noted by 
many observers (Friedberg, Donoso, and Stein, 1964; Lasser, Haft, and Friedberg, 1968; Scanlon, Pryor, and Blount, 1970; Ehsani et al., 1972). There is a well-recognized relation between Mobitz II block and third degree block. Narula et al. (I970a) described 13 patients with Mobitz II block, Io of whom had electrocardiographic evidence of abnormal intraventricular conduction. Four of these patients had complete heart block. The high incidence of intraventricular conduction disturbance with varied types of second degree block noted in our study $(74 \%, 14 / 19)$ has not been as well appreciated.

\section{References}

Cohen, S. I., Lau, S. H., Stein, E., Young, M. W., and Damato, A. N. (1968). Variations of aberrant ventricular conduction in man: evidence of isolated and combined block within the specialized conduction system. Circulation, 38, 899.

Damato, A. N., and Lau, S. H. (1970). Clinical value of the electrocardiogram of the conduction system. Progress in Cardiovascular Diseases, 13 , 119.

Damato, A. N., Lau, S. H., Helfant, R. H., Stein, E., Berkowitz, W. D., and Cohen, S. I. (1969). Study of atrioventricular conduction in man using electrode catheter recordings of His bundle activity. Circulation, 39, 287.

Davies, M., and Harris, A. (1969). Pathological basis of primary heart block. British Heart fournal, 31, 219.

Davies, M. J. (1971). Pathology of Conducting Tissue of the Heart. Butterworths, London.

Ehsani, A., Rosen, K., Dhingra, R., Loeb, H., and Rahimtoola, S. H. (1972). Sites of chronic heart block in adults clinical and electrocardiographic correlations (abstract). Circulation, 45 and 46, Suppl. II, 91.

Friedberg, C. K., Donoso, E., and Stein, W. G. (1964). Nonsurgical acquired heart block. Annals of the New York Academy of Sciences, III, 835.

Gershengorn, K., and Haft, J. I. (1972). Intermittent heart block related to treatment of hypertension in a patient with acute myocardial infarction. Chest, 6r, 402.

Gupta, P. K., Lichstein, E., and Chadda, K. D. (1973). Intraventricular conduction time ( $\mathrm{H}-\mathrm{V}$ interval) during antegrade conduction in patients with heart block. American fournal of Cardiology, 32, 27.

James, T. N. (1972). Sudden death related to myocardial infarction. Circulation, 45, 205.

Kuppersmith, J., Krongrad, E., and Waldo, A. L. (1973). Conduction intervals and conduction velocity in the human cardiac conduction system. Circulation, 47, 776.

Lasser, R. P., Haft, J. I., and Friedberg, C. K. (1968). Relationship of right bundle-branch block and marked left axis deviation (with left parietal and peri-infarction block) to complete heart block and syncope. Circulation, 37, 429.

Lenègre, J. (1962). Les blocs auriculo-ventriculaires fcomplets chroniques: étude des causes et des lésions à propos de 37 cas. Malattie Cardiovascolari, 3, $31 \mathrm{I}$.

Lenègre, J. (1964). Etiology and pathology of bilateral bundle branch block in relation to complete heart block. Progress in Cardiovascular Diseases, 6, 409.

Narula, O. S., and Samet, P. (1970). Wenckebach and Mobitz type II A-V block due to block within the His bundle and bundle branches. Circulation, 41, 947 .

Narula, O. S., Scherlag, B. M., Javier, R. P., Hildner, F. J., and Samet, P. (1970a). Analysis of the A-V conduction defect in complete heart block utilizing His bundle electrograms. Circulation, 41, 437.

Narula, O. S., Scherlag, B. J., and Samet, P. (1970b). Pervenous pacing of the specialized conducting system in man: His bundle and A-V nodal stimulation. Circulation, 41, 77.

Narula, O. S., Scherlag, B. J., Samet, P., and Javier, R. P. (1971). Atrioventricular block. American fournal of Medicine, 50, 146.

Nevins, D. B. (1972). First- and second-degree A-V heart block with rapid eye movement in sleep. Annals of Internal Medicine, 76, 98I.

Rosen, K. M., Loeb, H. S., Sino, M. Z., Rahimtoola, S. H., and Gunnar, R. M. (1971). Cardiac conduction in patients with symptomatic node disease. Circulation, 43, 836.

Rosenbaum, M. B., Elizari, M. V., and Lazzari, J. O. (1970). The Hemiblocks. Tampa Tracings, Oldsmar, Florida.

Samet, P., and Narula, O. S. (1970). Atrio-ventricular conduction defects in patients with sinus bradycardia (abstract). Circulation, 4I, Suppl. III, 42.

Scanlon, P. J., Pryor, R., and Blount, S. G., Jr. (1970). Right bundle-branch block associated with the left superior or inferior intraventricular block. Circulation, 42, I123.

Scherlag, B. J., Lau, S. H., Helfant, R. H., Berkowitz, W. D., Stein, E., and Damato, A. N. (I969). Catheter technique for recording His bundle activity in man. Circulation, 39, 13.

Scherlag, B. J., Narula, O. S., Lister, J. W., and Samet, P. (1970). Analysis of atrioventricular conduction by direct intracardiac recordings. Mount Sinai fournal of Medicine, 37, 266.

Scherlag, B. J., Samet, P., and Helfant, R. H. (1972). His bundle electrogram. Circulation, 46, 601.

Steiner, C., Lau, S. H., Stein, E., Wit, A. L., Weiss, M. B., Damato, A. N., Haft, J. I., Weinstock, M., and Gupta, P. (197I). Electrophysiologic documentation of trifascicular block as the common cause of complete heart block. American fournal of Cardiology, 28, 436.

Whiting, R. B., Klein, M. D., Vander Veer, J., and Lown, B. (1970). Variant angina pectoris. New England fournal of Medicine, 282, 709.

Requests for reprints to Dr. Stafford I. Cohen, Department of Medicine, Beth Israel Hospital, 330 Brookline Avenue, Boston, Massachusetts 02215, U.S.A. 